\title{
SOURCE PARAMETERS OF THE 28 OCTOBER 1983 BORAH PEAK, IDAHO, EARTHQUAKE FROM BODY WAVE ANALYSIS
}

\author{
By Diane I. Doser and Robert B. SMith
}

\begin{abstract}
Modeling of long-period body waves of the $M_{s}=7.3$ Borah Peak, Idaho, earthquake suggests that the earthquake was a simple rupture that nucleated at a depth of about $16 \mathrm{~km}$ and propagated unilaterally northwestward toward the surface. The seismic moment tensor obtained from the inversion of teleseismic body wave amplitude data agrees well with the fault plane solution obtained from short-period first motion data (strike, $138 \pm 3^{\circ}$; dip, $45 \pm 3^{\circ}$; rake, $-60 \pm 5^{\circ}$ ) and the observed surface faulting. The scalar double couple moment of $2.1 \times 10^{26}$ dyne-cm obtained from the inversion is comparable to a moment of $1.4 \times 10^{26}$ dyne-cm estimated from the observed surface faulting. Estimates of stress drop based on these values for the moment are 17 to 12 bars, respectively.
\end{abstract}

\section{INTRODUCTION}

The $M_{S}=7.3$ Borah Peak, Idaho, earthquake is the largest earthquake to have occurred in the Intermountain Seismic Belt since 1959, making it the first large $(M>7.0)$ normal fault earthquake in the region to have been well recorded at regional and teleseismic distances. Study of this earthquake will provide information needed to develop a model for future normal fault earthquakes expected to occur in other parts of this region of intraplate extension.

Long-period body waves recorded at teleseismic distances $\left(25^{\circ}<\Delta<90^{\circ}\right)$ were modeled to determine the focal depth and source-time function for the main shock. Receiver amplitudes for direct and near-source reflected phases, also obtained in the modeling process, were inverted to obtain a seismic moment tensor. These results are compared with source parameters obtained from surface faulting, aftershock patterns, and short-period body wave data.

\section{Regional Tectonic Setting}

The main shock of the 1983 Borah Peak earthquake sequence occurred along the Lost River fault at the base of the Lost River Range in an area of Basin-Range type faulting $50 \mathrm{~km}$ northwest of the Snake River Plain (Figure 1). Adjacent mountain ranges consist of Precambrian and Paleozoic sedimentary rocks that were highly deformed by thrust faults during the Mesozoic (Ruppel, 1982). There is good evidence for repeated movement along the Lost River fault in the last 10,000 to $100,000 \mathrm{yr}$ (Hait and Scott, 1978). Historically, however, the region had been aseismic prior to the 1983 main shock.

Surface faulting that occurred during the earthquake is shown in Figure: 2 along with epicenters for the main shock and aftershocks of $M_{L}=>4.0$ occurring during the first 2 months of the sequence (Smith et al., 1985). The southernmost and longest segment of surface faulting begins to the north of the main shock epicenter and follows the trace of the Lost River scarp for $19 \mathrm{~km}$. Five kilometers northwest of this segment surface faulting resumes along a 8-km-long segment. To the west of this gap in faulting, a series of shorter scarps trend generally west-northwest. The average throw along the scarps is $0.8 \mathrm{~m}$ and exceeds $1.0 \mathrm{~m}$ along 43 per cent of their length (Crone et al., 1985). Grooves on the southern segment of the fault 


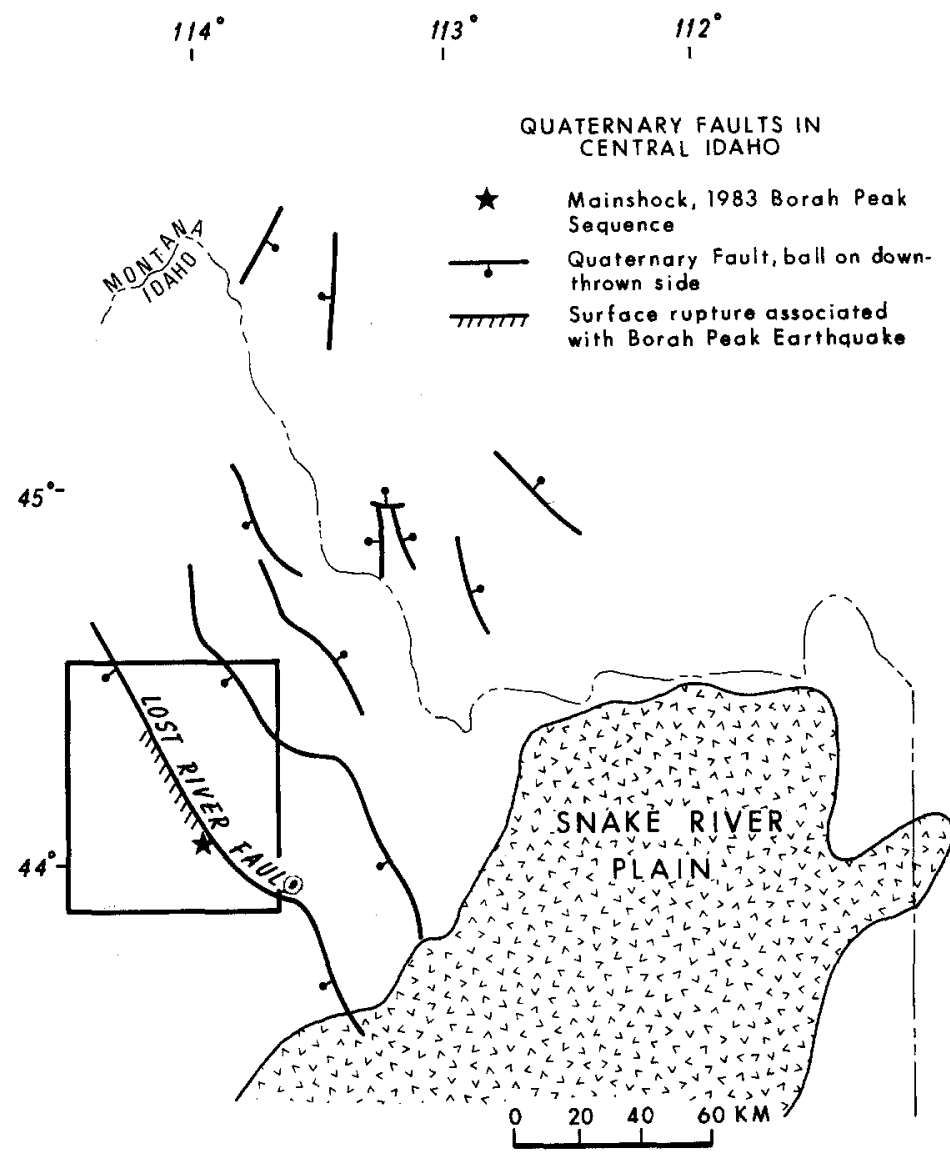

FiG. 1. Map showing location of major Quarternary faults in central Idaho. Fault locations are from Ruppel (1982) and Scott et al. (1985). Area enclosed in box is shown in Figure 2.

indicate a left-lateral component of strike-slip motion that is about 17 per cent of the dip-slip component (Crone et al., 1985). The location of the main shock $15 \mathrm{~km}$ southwest of the surface faulting suggests unilateral rupture propagation to the northwest (Smith et al., 1984).

\section{Body Wave Modeling and Moment Tensor Inversion}

Forward modeling of long-period $P$ waves from the Borah Peak main shock are used to determine receiver amplitudes for $P, p P$, and $s P$ phases following the method of Fitch et al. (1980). The receiver amplitudes are later used to invert for a seismic moment tensor. Stations used in the modeling process are listed in Table 1.

The modeling procedure consisted of several steps. First, the mean amplitude is removed from the observed digital $P$ waveform. Next a synthetic waveform is generated for each station by superimposing $P, p P$, and $s P$ wavelets that have the same trapezoidal source-time function and are delayed with respect to one another by times corresponding to a given depth. The heights of the trapezoids are related to $P, p P$, and $s P$ receiver amplitudes and are used as input in the inversion for a seismic moment tensor. The superposition of trapezoids is convolved with an instrumental transfer function and a causal $Q$ operator to produce a synthetic seismogram that is then compared with the original waveform. The heights of the 


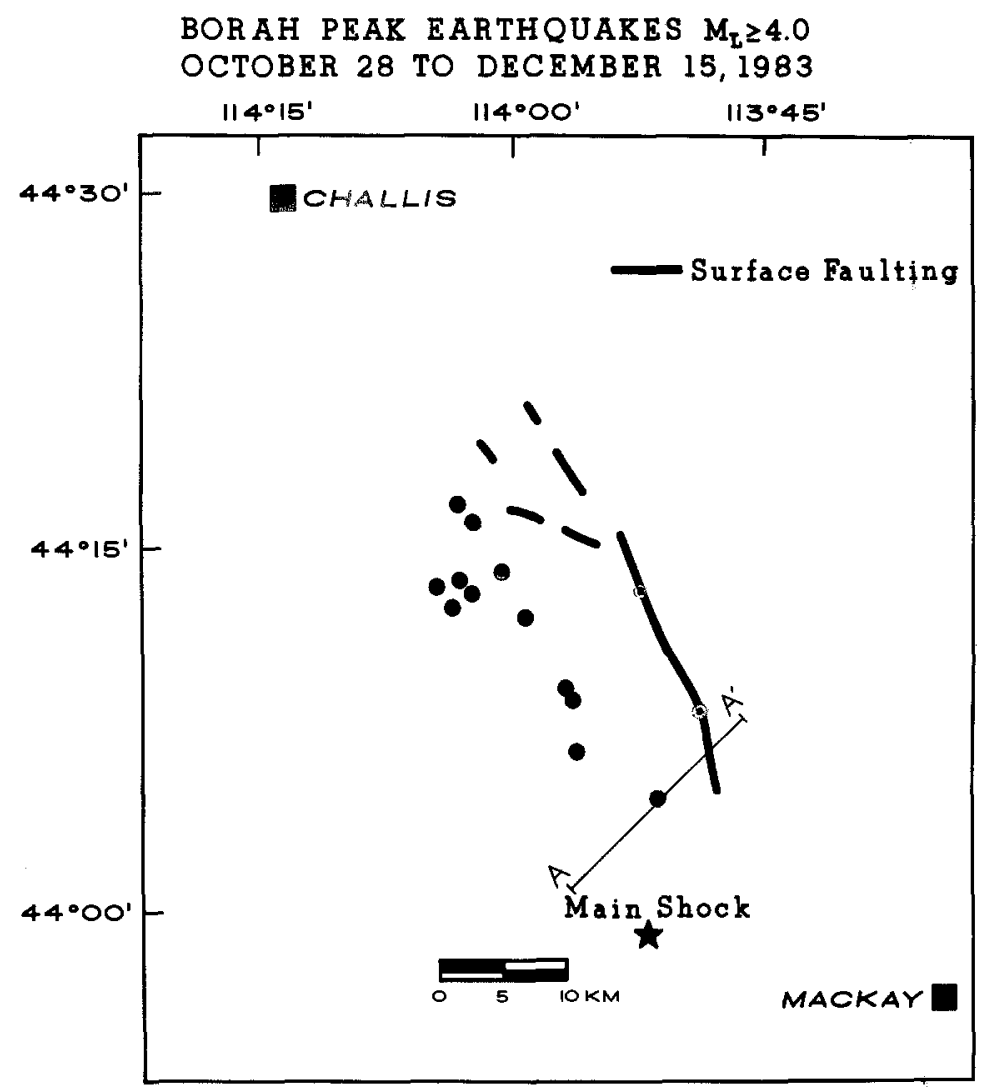

FIG. 2. Sưface faulting (Crone et al., 1985) and epicenters of the main shock and aftershocks of the Borah Peak, Idaho, earthquake sequence with $M_{L} \geqq 4.0$ (Smith et al., 1985). A cross-section of aftershocks along line $A-A^{\prime}$ is shown in Figure 7.

TABLE 1

Stations Used in Waveform Modeling and Moment TENSOR INVERSION

\begin{tabular}{lrrl}
\hline Station & Distance $\left(^{\circ}\right)$ & Azimuth $\left(^{\circ}\right)$ & Phases Used \\
\hline elk & 3.4 & 197.2 & fm \\
dug & 3.9 & 167.6 & fm \\
mnv & 6.4 & 211.3 & fm \\
rssd & 7.1 & 85.8 & fm \\
gol & 7.7 & 121.2 & fm \\
jas & 7.7 & 221.4 & fm \\
lac & 9.8 & 192.2 & fm \\
anmo & 10.7 & 145.1 & fm \\
rson & 15.3 & 56.3 & fm \\
rsnt & 18.5 & 359.0 & fm \\
rscp & 23.3 & 101.5 & fm \\
scp & 26.7 & 84.3 & $P$ \\
rsny & 28.0 & 75.0 & $P$ \\
col & 28.1 & 329.7 & $P$ \\
gdh & 39.3 & 29.3 & $P$ \\
hon & 42.8 & 252.6 & $P$ \\
boco & 52.6 & 126.5 & $P$ \\
ber & 64.8 & 28.6 & $P$ \\
kono & 66.0 & 27.4 & $P$ \\
zobo & 73.1 & 134.0 & $P$ \\
grfo & 75.1 & 33.3 & $P$ \\
tol & 75.3 & 40.4 & $P$ \\
majo & 76.6 & 308.0 & $P$ \\
afi & 78.0 & 237.2 & $P$ \\
bdf & 84.4 & 117.8 & $P$ \\
\hline$P$ P & & & \\
\hline
\end{tabular}

* $P, P$ wave; fm, first motion polarity from long-period instrument. 

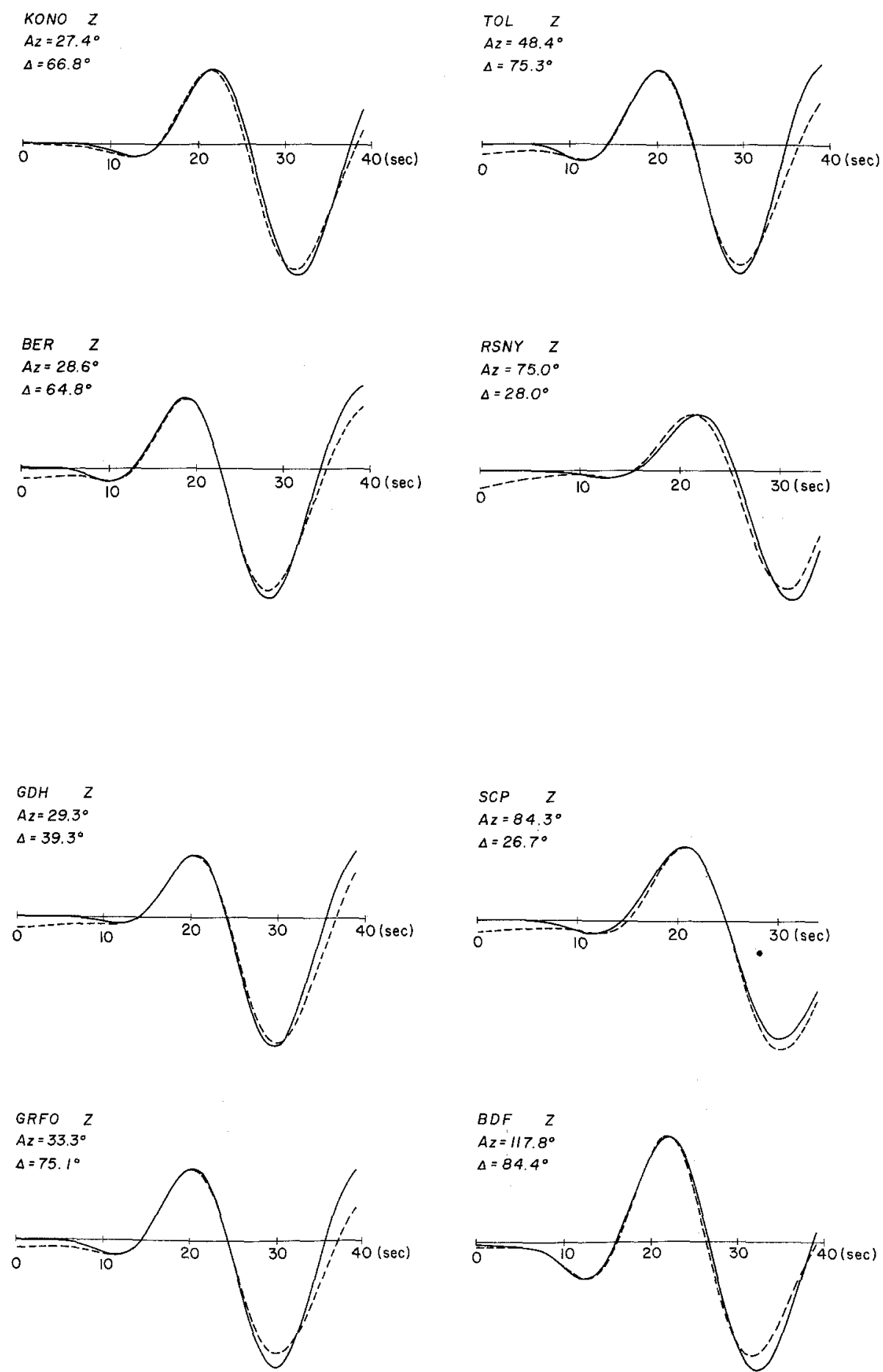

Fig. 3. Synthetic (dashed line) and observed (solid line) seismograms for the Borah Peak main shock The station azimuths $(\mathrm{Az})$ and epicentral distances $(\Delta)$ are listed above the individual seismograms. 
trapezoids (the phase amplitudes), the duration of the source time function, and the focal depth are varied until a satisfactory fit between the synthetic and the observed seismogram is obtained. Goodness of fit is determined by examining the cross-correlation of the data with the synthetic seismogram. This process differs from that of Kanamori and Stewart (1976) in that no assumptions are made about the source orientation or moment in the modeling process. This information is extracted from the phase amplitudes during the inversion for the seismic moment tensor.

The $p P-P$ and $s P-P$ delay times used to generate synthetics were obtained from the Jeffreys-Bullen (1940) tables and are interpolated at intervals of $1 \mathrm{~km}$ from 1 to $25 \mathrm{~km}$ in depth and $1^{\circ}$ in distance. Anelastic attenuation is calculated using a $t^{*}$ (attenuation factor) value of 1.0 (Kanamori and Stewart, 1976).

A trial-and-error method is used to obtain estimates of source-time function duration and focal depth that best fit the general waveform shape at each station. From these estimates, the average source-time function (4 sec rise, $3 \mathrm{sec}$ plateau, 4 sec fall) and focal depth $(16 \mathrm{~km})$, are obtained. These values were then used in modeling for the $P, p P$, and $s P$ amplitudes at each station. Variations of less than $3 \mathrm{~km}$ in focal depth and $1.0 \mathrm{sec}$ in source-time function duration did not produce noticeable variations in the cross-correlation fit of seismograms, and hence provide an informal measure of uncertainty in the estimates. Results of modeling all the $P$ waveforms are shown in Figures 3 and 4. The simple shape of the waveform and the excellent match between the data and synthetics at various azimuths suggest that the long-period rupture process had no major complexities.

Inversions for seismic moment tensors used the minimization of the $L 1$ norm, a summation of absolute values of residuals, as the optimum solution criterion (Fitch et al., 1980; Fitch, 1981) allowing first motion polarities to be included in the data set to help constrain the solution. Use of this minimization is also more robust than the minimization of the sum of squared residuals ( $L 2$ norm) (Claerbout and Muir, 1973). The inclusion of amplitudes from near-source reflected phases provides coverage of the upper hemisphere, reducing errors in the inversion process. Standard error for the moment tensor components cannot be estimated using the method of Fitch et al. (1980), however test inversions run on synthetic amplitude data suggest an informal uncertainty of $\pm 5^{\circ}$ in the strike and dip of the nodal planes obtained in this process.

Phase amplitudes obtained in the modeling process were reduced to the focal sphere by normalizing to a distance of $60^{\circ}$ using the amplitude-distance functions of Sengupta (1975) and the geometrical spreading correction of Bullen (1963). Corrections for free surface effects (Bullen, 1963; Ewing et al., 1957) at the receiver and near the source, if appropriate, were also made. Near-source and receiver structures were approximated by elastic half-spaces. The receiver $P$-wave velocity was set at $5 \mathrm{~km} / \mathrm{sec}$. A hypocentral $P$-wave velocity of $6.5 \mathrm{~km} / \mathrm{sec}$, based on the velocity model of Sparlin et al. (1982) for the southeastern end of the Lost River Valley, was used. Moment tensor solutions are listed in Table 2. The scalar moment for the earthquake was $2.1 \times 10^{26}$ dyne-cm.

In addition to modeling long-period body waves, short-period body wave information was used to determine the focal depth and fault plane solution for the Borah Peak event. The focal mechanism obtained using regional and teleseismic first motion data is shown in Figure 5. Take-off angles were estimated using a Herrin (1968) velocity model. The best fit to the data is a solution with strike of 

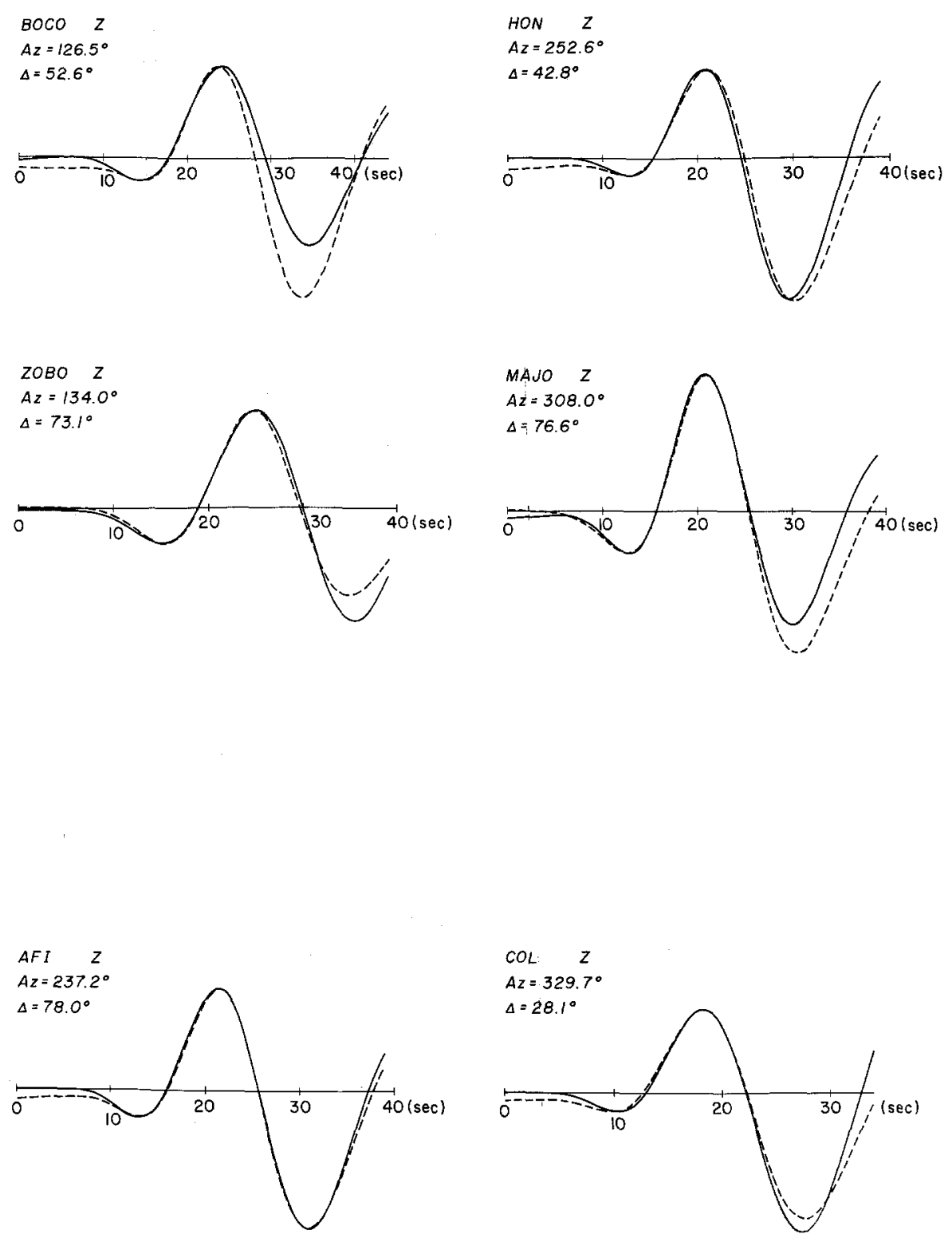

FIG. 4. Synthetic (dashed line) and observed (solid line) seismograms for the Borah Peak main shock.

TABLE 2 UnConstrained and Constrained Moment Tensor Solutions

\begin{tabular}{lllllll}
\hline \multicolumn{1}{c}{ Solution } & $\mathrm{Mnn}^{*}$ & Mne & Mee & Mnz & Mez & Mzz \\
\hline Unconstrained & 2.2 & 1.4 & 2.1 & 0.37 & -0.45 & -1.5 \\
Constrained & 0.81 & 1.4 & 0.78 & 0.61 & -0.83 & -1.6 \\
\hline \multicolumn{1}{c}{ Solution } & Res $\dagger$ & $\% \mathrm{M} \ddagger$ & $\% \mathrm{DC} \neq$ & $\% \mathrm{CLVD}$ & \multicolumn{2}{c}{ Scalar Moment* } \\
\hline Unconstrained & 0.18 & 26 & 72 & 2 & \multicolumn{2}{c}{1.6} \\
Constrained & 0.26 & & & & 2.1 \\
\hline
\end{tabular}

* Multiply by $1 \times 10^{26}$ for dyne-cm.

$\dagger$ Absolute average residual, pertains to amplitude data only.

$\ddagger \% \mathrm{M}$, per cent monopole; \%DC, per cent dipole; \%CLVD, per cent compensated linear vector dipole. 


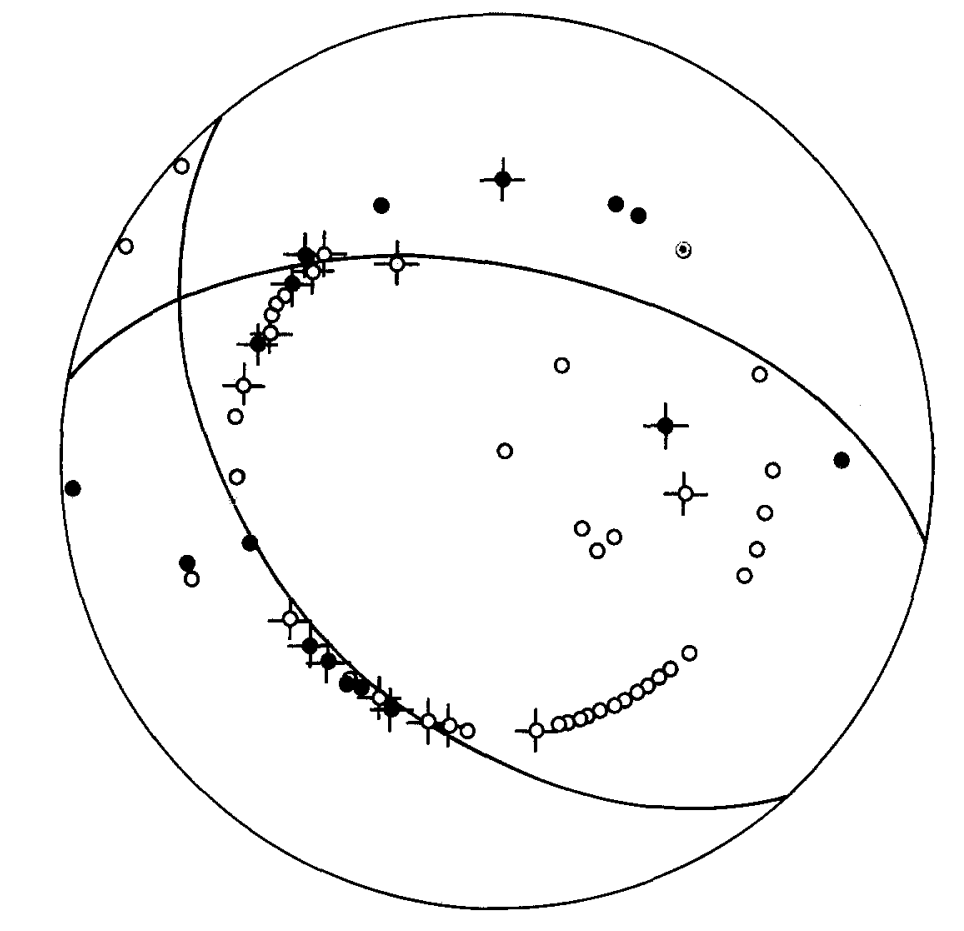

FOCAL MECHANISM FROM SHORT-PERIOD DATA

FIG. 5. Fault plane solution from short-period first motion data. The focal mechanism is a lower hemisphere projection where open circles indicate dilatation and dark circles, compression. Near-nodal motions are indicated by crosses.

TABLE 3

$p P-P$ TIMES FROM SHORT- AND INTERMEDIATE-PERIOD INSTRUMENTS

\begin{tabular}{lcrrr}
\hline Station & $\begin{array}{c}p P-P \text { Time } \\
(\mathrm{sec})\end{array}$ & $\begin{array}{c}\text { Distance } \\
\left({ }^{\circ}\right)\end{array}$ & \multicolumn{1}{c}{$\begin{array}{c}\text { Depth* } \\
(\mathrm{km})\end{array}$} & $\begin{array}{c}\text { Instrument } \\
\text { Type }\end{array}$ \\
\hline boco & $4.0 \pm 0.5$ & 52.6 & $13 \pm 2$ & s.p. \\
col & $4.5 \pm 0.3$ & 28.1 & $16.5 \pm 1$ & i.p. \\
grfo & $4.0 \pm 0.5$ & 75.1 & $13 \pm 2$ & s.p. \\
majo & $4.7 \pm 0.5$ & 76.6 & $15.5 \pm 2$ & s.p. \\
rscp & $3.8 \pm 0.5$ & 23.3 & $14 \pm 2$ & s.p. \\
rsnt & $4.5 \pm 0.5$ & 18.5 & $16.5 \pm 2$ & s.p. \\
rsny & $5.0 \pm 0.5$ & 28.0 & $18 \pm 2$ & i.p. \\
tol & $4.8 \pm 0.5$ & 75.3 & $16 \pm 2$ & i.p. \\
zobo & $4.0 \pm 0.5$ & 73.1 & $13 \pm 2$ & s.p. \\
\hline
\end{tabular}

* Estimated from the Jeffreys-Bullen (1940) table.

$\doteqdot$ s.p., short-period; i.p., intermediate-period.

$138 \pm 3^{\circ}$, dip of $45 \pm 3^{\circ}$, and rake of $60 \pm 5^{\circ}$. Short-period data also gave $p P-P$ times listed in Table 3. The average focal depth of $15.4 \pm 0.6 \mathrm{~km}$ agrees well with the focal depth obtained from long-period data.

\section{Discussion}

A comparison of the double-couple component of the unconstrained moment tensor with the constrained moment tensor and the fault plane solution from shortperiod first motion data is shown in Figure 6. Although the unconstrained moment tensor was only 72 per cent double couple, the strike and dip of the southwest- 
dipping nodal plane of the double-couple component is similar to the short-period fault plane solution. The unconstrained solution has a smaller component of strikeslip motion, causing a strike difference of $23^{\circ}$ in the northeast-dipping planes of the solutions. The nodal planes of the constrained solution are similar to the fault plane solution except the constrained solution is rotated $25^{\circ}$ to the northwest with respect to the short-period fault plane solution. Both solutions exhibit a similar component of left-lateral strike-slip motion. The good agreement between the moment tensors and the fault plane solution suggest that the rupture occurred along a fault plane with a strike of $138^{\circ}$ to $163^{\circ}$, dip of $45^{\circ}$ to $53^{\circ}$, and rake of $-57^{\circ}$ to $-72^{\circ}$. These parameters are consistent with the main surface trace of the fault that strikes 160 $\pm 10^{\circ}$ and is observed to have a small component of left-lateral strike-slip motion. The dip of $45^{\circ}$ to $53^{\circ}$ is also consistent with a cross-section of aftershock hypocenters (Figure 7) taken perpendicular to the fault strike (line $A-A^{\prime}$ in Figure 2).
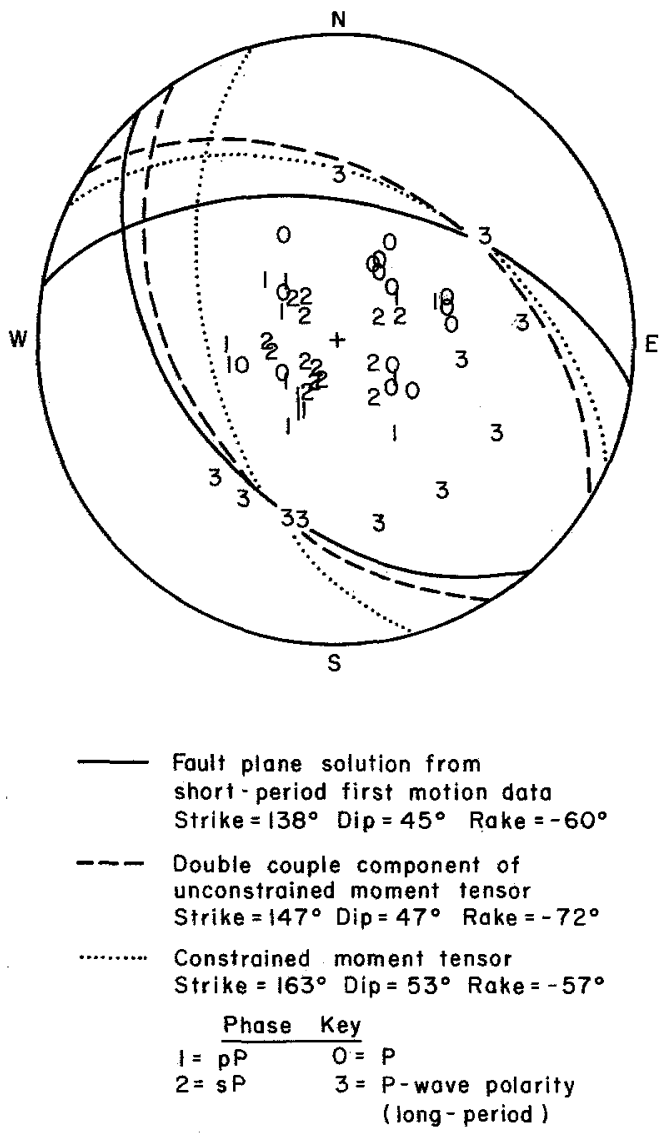

FIG. 6. Comparison of fault plane solution from short-period first motion data with constrained and unconstrained moment tensor solutions. Numbers refer to phase amplitudes used in the moment tensor inversion.

The focal depths of most aftershocks were generally less than $12 \mathrm{~km}$, although a few had focal depths as deep as $16 \mathrm{~km}$ (Smith et al., 1985). If fault plane is projected dipping at $45^{\circ}$ west from the surface break, the main shock epicenter is projected onto the line $A-A^{\prime}$ and downward to the fault plane, the depth where the projection 
and fault plane meet is about $16 \mathrm{~km}$. A depth of 22 to $23 \mathrm{~km}$ is obtained for a fault plane dipping $53^{\circ}$.

For a unilateral rupture model, where $v$ is the rupture velocity and $t_{c}$ is the rupture time (the rise time plus the plateau time), the fault length, $L$, can be estimated from $t_{\mathrm{c}} \sim L / v$. Using a rupture velocity of $3 \mathrm{~km} / \mathrm{sec}$, a fault length of $21 \mathrm{~km}$ is obtained, which is comparable to the 19-km-long southernmost segment of surface faulting. This suggests that the unilateral rupture model is appropriate for this earthquake.

The average displacement, $D$, along the fault can be estimated from $D=$ $M_{0} / \mu w L$, where $M_{0}$ is the seismic moment, $w$ is the fault width, and $\mu$ is the shear modulus $\left(3.3 \times 10^{11}\right.$ dyne- $\left.\mathrm{cm}^{2}\right)$. The fault width, assuming a dip of $45^{\circ}$ and a maximum vertical extent of $16 \mathrm{~km}$, is $22.6 \mathrm{~km}$. Using these values, a scalar doublecouple moment of $2.1 \times 10^{26}$ dyne-cm from the moment tensor inversion and the seismically determined fault length of $21 \mathrm{~km}$, the estimated displacement is $1.4 \mathrm{~m}$. The maximum observed surface displacement is $2.7 \mathrm{~m}$, and the average displacement along the southernmost segment is about $1.0 \mathrm{~m}$ (Crone et al., 1985). The average observed surface displacement of $1.0 \mathrm{~m}$ gives a moment estimate of $1.4 \times 10^{26}$ dyne$\mathrm{cm}$, using a fault width of $22.6 \mathrm{~km}$ and a fault length of $19 \mathrm{~km}$ that corresponds to

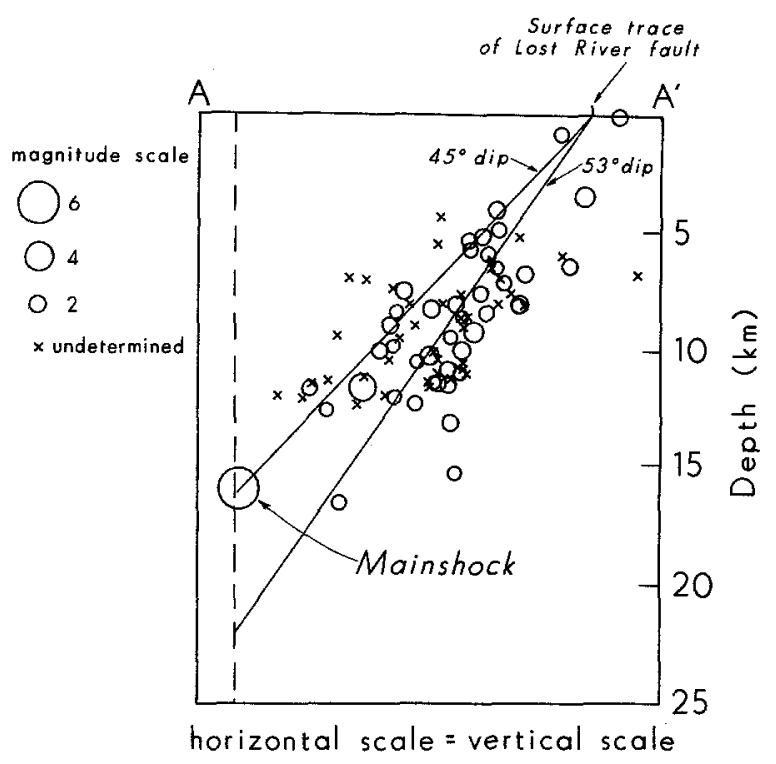

FIG. 7. Cross-section of hypocenters along $A-A^{\prime}$. The epicenter of the main shock is projected on the cross-section. A range of possible fault plane dips based on fault plane solution and moment tensor results is also shown.

the longest continuous segment of surface faulting. Although this moment value is 30 per cent lower than the seismologically determined value, it is within the limits of error associated with these estimates.

The stress drop, $\Delta \sigma$, was estimated from, $\Delta \sigma=8 M_{0} / 3 \pi w^{2} L$ (from Starr, 1928). The seismologically determined moment gives a stress drop of 17 bars, and the geologically determined moment gives a stress drop of 12 bars. These values are comparable to a stress drop of 20 bars observed for the $M_{S}=6.0$ Pocatello Valley, Idaho, earthquake (Bache et al., 1980), but lower than a seismologically determined stress drop of 115 bars for the $1959\left(M_{S}=7.5\right)$ Hebgen Lake, Montana, mainshock 
(Doser, 1985). Even considering possible sources of error in the stress drop estimation, it is unlikely that the stress drop exceeds 75 bars for the Borah Peak main shock, suggesting that the earthquake was a low stress drop event when compared to normal fault earthquakes in the same magnitude range.

\section{CONCLUSIONS}

The study of long-period body waves of the Borah Peak earthquake has given source parameter estimates that are comparable to parameters obtained from studies of surface faulting and aftershock distribution. These data suggest that the rupture began at a depth of 15 to $16 \mathrm{~km}$ and propagated unilaterally to the northwest along a fault plane dipping $45^{\circ}$. No subevents or rupture complexities were observed in the long-period data. Stress drops estimated from geologic and seismologic data suggest that the earthquake was a low stress drop event. These observations are currently being used in conjunction with the results of studies of other intermountain earthquakes to develop a model for large normal fault earthquakes expected to occur in other parts of the region.

\section{ACKNOWLEDGMENTS}

We would like to thank W. D. Richins for providing aftershock information and useful comments. J. C. Pechmann, M. R. Baker, and H. Kanamori also gave helpful suggestions and comments. U. Vetter, J. Zollweg, S. R. Taylor, and T. Wallace kindly provided seismograms and/or first motion polarities for use in the fault plane solution determination. Comments from an anonymous reviewer are also appreciated. This work was supported by the U.S. Geological Survey Earthquake Hazards Reduction Program Contract to the University of Utah (14-08-0001-21856).

\section{REFERENCES}

Bache, T. C., D. G. Lambert, and T. G. Barker (1980). A source model for the March 28, 1975 Pocatello Valley earthquake from time-domain modeling of the teleseismic $P$ waves, Bull. Seism. Soc. Am. 70, 405-418.

Bullen, K. E. (1963). An Introduction to the Theory of Seismology, Cambridge University Press, Cambridge, England.

Claerbout, J. F. and F. Muir (1973). Robust modeling with erratic data, Geophysics 83, 826-844.

Crone, A. J., M. N. Machette, M. G. Bonilla, J. J. Lienkaemper, R. C. Bucknam, K. L. Pierce, and W. E. Scott (1985). Characteristics of surface faulting accompanying the Borah Peak earthquake, central Idaho, in Workshop XXVIII on the Borah Peak earthquake, U.S. Geol. Surv., Open-File Rept. 85-290, 43-58.

Doser, D. I. (1985). Source parameters and faulting processes of the 1959 Hebgen Lake, Montana earthquake sequence, J. Geophys. Res. (in press).

Ewing, M., W. Jardetzky, and F. Press (1957). Elastic Waves in Layered Media, McGraw-Hill, New York.

Fitch, T. J. (1981). Correction and addition (to Fitch et al., 1980), J. Geophys. Res. 86, 9375-9376.

Fitch, T. J., D. W. McCowan, and M. W. Shields (1980). Estimation of the seismic moment tensor from teleseismic body wave data with applications to intraplate and mantle earthquakes, J. Geophys. Res. 85, 3817-3828.

Hait, M. H., Jr. and W. E. Scott (1978). Holocene faulting, Lost River Range, Idaho (abstract), Geol. Soc. Am. Abs. with Prog. 10, 217.

Herrin, E. (1968). 1968 Seismological tables for $P$ phases, Bull. Seism. Soc. Am. 58, 1193-1241.

Jeffreys, H. and K. E. Bullen (1940). Seismological Tables, British Association for the Advancement of Science, London, England.

Kanamori, H. and G. S. Stewart (1976). Mode of strain release along the Gibbs fracture zone, MidAtlantic Ridge, Phys. Earth. Planet. Interiors 11, 312-332.

Ruppel, E. T. (1982). Cenozoic block uplifts in east-central Idaho and southwest Montana, U.S. Geol. Surv. Profess. Paper 1224, 24 pp.

Sengupta, M. K. (1975). The structure of the earth's mantle from body wave observation, Ph.D. Thesis, Massachusetts Institute of Technology, Cambridge, Massachusetts. 
Scott, W. E., K. L. Pierce, and M. H. Hait, Jr. (1985). Quaternary tectonic setting of the 1983 Borah Peak earthquake, Central Idaho, in Workshop XXVII on the Borah Peak earthquake, U.S. Geol. Surv., Open-File Rept. 85-290, 1-16.

Smith, R. B., W. D. Richins, D. I. Doser, J. C. Pechmann, and C. Langer (1984). The $1983 M_{S}=7.3$ Borah Peak, Idaho, earthquake: a model for active crustal extension (abstract), Geol. Soc. Am. Abstr. with Prog., 16, 661.

Smith, R. B., W. D. Richins, and D. I. Doser (1985). The 1983 Borah Peak, Idaho, earthquake: regional seismicity, kinematics of faulting, and tectonic mechanism, in Workshop XXVIII on the Borah Peak Earthquake, U.S. Geol. Surv., Open-File Rept. 85-290, 236-263.

Sparlin, M. A., L. W. Braile, and R. B. Smith (1982). Crustal structure of the eastern Snake River Plain determined from ray trace modeling of seismic refraction data, J. Geophys. Res. 82, 3665-3676.

Starr, A. T. (1928). Slip in a crystal and rupture in a solid due to shear, Proc. Cambridge Phil. Soc. 24, 489-500.

SEISMOLOGICAL LABORATORY

California Institute of Technology

Pasadena, California 91125 (D.I.D.)
DEPARTMENT OF GEOPHYSICS

UNIVERSITY OF UTAH

SALT LAKE CITY, UTAH 95521 (R.B.S.)

Manuscript received 12 October 1984 